\title{
FROM THE INSIDE
}

\section{Chrysalis}

\section{Catherine Proulx*}

C 2021 Springer-Verlag GmbH Germany, part of Springer Nature

\section{Chrysalis}

I've always liked butterflies.

They're free, just like me.

Until now.

I'm spinning. I can't move.

Weaving my cocoon.

Captive, through lines of silk.

I'm not alone, I know.

I'm brave, they say.

And I'm not afraid of the dark.

Times have changed.

Time has come.

For metamorphosis.

Cracks, at last.

And through the gaps.

I see light.

My senses transcend.

Antennae on my bald scalp.

Guide me through obscurity.

I feel them growing through my spine.

Wrapping tenderly around my scars.

No more pain.

Weightlessness.

An explosion of colors.

Radiance through the dusk.
Look at me.

Pale and lucent skin.

Alive again.

My eyes are closed but I'm flying.

Don't worry, mommy and daddy.

I am ready.

Chrysalis is inspired by a true story about a loving mother and her terminally ill son. She helped him to understand his sickness using the metaphor of the butterfly, which undergoes a transformative period of immobility and physical change to become mobile and free. Near the end of his life, the child truly felt that he was metamorphosing into a butterfly and verbalized that he was feeling his wings grow until he was ready to "leave".

\section{Acknowledgements}

To Kay Min, Briseida Mema and my dear colleagues for nurturing reflection about our personal and professional journeys through the "Literary Arts in Critical Care" Curriculum; with gratitude to the University of Toronto's Faculty of Medicine for supporting this project via the Medical Humanities Education Grant

Funding

University of Toronto's Faculty of Medicine, 2020 Medical Humanities Education Grant.

\section{Declarations}

Conflicts of interest

None.

\section{Publisher's Note}

Springer Nature remains neutral with regard to jurisdictional claims in published maps and institutional affiliations.

Received: 8 May 2021 Accepted: 23 May 2021

Published online: 16 June 2021

\section{Springer}

